\title{
MARKETING DE RELACIONAMENTO COM A APPLE: O PAPEL DO JULGAMENTO E SIGNIFICADO DE PRODUTO NA ESCOLHA DO iPHONE
}

\author{
Gisela Demo* \\ giselademo@gmail.com \\ Morgana Guanabara* \\ morgana.guanabara@gmail.com \\ *Universidade de Brasília - Brasília, DF
}

http://dx.doi.org/10.1590/1413-2311.0042014.46930

Recebido em 06/03/2014

Aprovado em 09/03/2015

Disponibilizado em 01/04/2015

Avaliado pelo sistema double blind review

Revista Eletrônica de Administração

Editor: Luís Felipe Nascimento

ISSN 1413-2311 (versão on line)

Editada pela Escola de Administração da Universidade Federal do Rio Grande do Sul.

Periodicidade: Quadrimestral

Sistema requerido: Adobe Acrobat Reader.

\section{RESUMO}

Em um cenário de competitividade recrudescente, a gestão de relacionamento com clientes (CRM) apresenta-se como profícuo diferencial organizacional. A maneira pela qual os consumidores processam seu julgamento, passo-a-passo ou afetivo, e atribuem significados, utilitário ou simbólico, a produtos é particularmente relevante para entender seu comportamento de consumo e seu relacionamento com as marcas. Igualmente importante é a tomada de decisões realizada com base nesse processo. Haja vista a escassez na literatura de estudos científicos que relacionem o CRM a variáveis de comportamento do consumidor, esse estudo, de natureza quantitativa, teve como objetivo identificar se o relacionamento dos consumidores com a Apple pode ser influenciado pelo julgamento e significado que eles atribuem ao produto iPhone. Os resultados mostraram a influência do julgamento afetivo no estabelecimento do relacionamento com a marca. Além disso, foi possível concluir que os usuários pesquisados são influenciados mormente pelo julgamento passo-a-passo e dão mais importância ao significado utilitário no processo de escolha e compra do iPhone. Quanto à percepção do relacionamento com a Apple, os respondentes demonstraram que a alta qualidade dos smartphones vendidos pela marca e a confiança na marca são os fatores mais preponderantes na sua escolha. A contribuição acadêmica deste trabalho reside em preencher a lacuna na literatura ao identificar antecedentes do CRM. Outrossim, em uma perspectiva gerencial, tanto para a Apple como para outras fabricantes de smartphones, os resultados por ora obtidos podem ser utilizados como diagnóstico para auxiliar os gestores em suas estratégias de promoção de produtos e fidelização de clientes.

Palavras-chave: marketing de relacionamento; CRM; julgamento e significado de produto; Apple; iPhone 


\title{
RELATIONSHIP MARKETING WITH APPLE: THE ROLE OF MEANING AND JUDGMENT OF PRODUCT IN CHOOSING THE IPHONE
}

\begin{abstract}
In a scenario of growing competitiveness, customer relationship management (CRM) is presented as an effective competitive advantage. The manner in which consumers process their judgment, either rational or emotional, and attribute meanings, either objective or symbolic, to products is particularly relevant to understanding consumer behavior and their relationship with brands. Equally important are the decision-making styles. Considering the lack of scientific studies correlating CRM variables to consumer behavior ones, this quantitative study aimed to identify if the relationship among Apple and its costumers might be influenced by the meaning and judgement they attribute to the smartphone iPhone. The results showed the influence of the emotional judgment on establishing the relationship with the brand. Furthermore, it was concluded that the specific sample surveyed is influenced mainly by rational judgement whereas they impute more importance to objective meaning when purchasing an iPhone. Regarding the perception of the relationship with Apple, the respondents indicated that higher quality of the iPhones as well as their trust on the brand are the most important aspects that influence their choice. The academic contribution of this work is to fill the gap in the literature by identifying CRM predictors. Also, as a managerial perspective, for both Apple and other smartphone companies, the results obtained so far can be used as a diagnostic to assist managers in their strategies concerning product promotion and customer loyalty.
\end{abstract}

Keywords: relationship marketing; customer relationship management (CRM); meaning and judgement of products; Apple; iPhone

\section{MARKETING DE RELACIONAMIENTO CON APPLE: JUZGAMIENTO Y SIGNIFICADO DEL PRODUCTO EN LA ESCOJA DEL $i P H O N E$}

\begin{abstract}
RESUMEN
En un escenario de competitividad creciente, gestión de relacionamiento con clientes (CRM) presentase como diferencial provechoso organizacional. La manera en la cual consumidores procesan su juzgamiento, paso a paso o afectivo, y atribuyen significados, utilitario o simbólico, a producto es particularmente relevante para entender su comportamiento de consumo y su relacionamiento con las marcas. Similarmente importante es la toma de decisiones realizada con base en este proceso. En vista de la escasez en la literatura de estudios científicos que relacionen CRM a variables de comportamiento del consumidor, este estudio cuantitativo tuve como objetivo identificar si el relacionamiento de los consumidores con Apple puede ser influenciado por el juzgamiento y significado que ellos atribuyen al producto iPhone. Los resultados muestran la influencia del juzgamiento afectivo en el establecimiento del relacionamiento con la marca. Además, fue posible concluir que los usuarios investigados son influenciados principalmente por el juzgamiento paso a paso y dan más importancia al significado utilitario en el proceso de escoja y compra del iPhone. Cuanto a la percepción del relacionamiento con Apple, os respondientes demuestran que la alta calidad de los smartphones vendido por la marca y la confianza en la marca son los factores más preponderantes en su escoja. La contribución académica de este trabajo reside en llenar una brecha en la literatura, identificando predictores de CRM. Igualmente, en una perspectiva gerencial, tanto para Apple como para otros fabricantes de smartphones, los resultados ahora
\end{abstract}

$$
\text { REAd | Porto Alegre - Edição } 80 \text { - N } 1 \text { - janeiro/abril } 2015 \text { - p. 170-199 }
$$


Marketing de relacionamento com a Apple: o papel do julgamento e significado de produto na escolha do iPhone

obtenidos pueden ser utilizados como diagnóstico para auxiliar los gestores en sus estrategias de promoción de productos y lealtad de clientes.

Palabras-clave: marketing de relacionamiento; CRM; juzgamiento y significado de producto; Apple; iPhone.

\section{INTRODUÇÃO}

A partir da década de 90, pode-se afirmar que houve uma mudança significativa no mercado de bens e serviços que trouxe consigo novos comportamentos, oportunidades e desafios. A competitividade torna os consumidores mais exigentes, porque acarreta em diversas alternativas de consumo, o que obriga o empenho das empresas em garantir a melhor oferta para o cliente (DEMO; ROZZETT, 2013).

Dessa forma, visando à prosperidade das empresas por meio de sua capacidade de se reinventar, os relacionamentos entre organizações e clientes adquirem conotação especial e o CRM (Customer Relationship Management) ou Marketing de Relacionamento, englobando aspectos da satisfação e da lealdade de clientes em conjunto com a constante oferta de experiências únicas e encantadoras, apresenta-se como diferencial essencial quando a questão é competitividade (DEMO, 2014).

Conforme Allen (2001), a maneira pelo qual os consumidores processam seu julgamento e atribuem significado aos produtos é particularmente relevante para entender seu comportamento de consumo. Igualmente importantes são as tomadas de decisão feitas com base nesse processo (RICHINS, 1994). De acordo com Allen (2001), a atribuição de significado a um produto baseia-se no tipo de julgamento utilizado pelos consumidores, considerando componentes racionais (atributos específicos de utilidade) e emocionais (intuitivos e holísticos). Fournier (1991) e Allen (1997) ressaltam que, em linhas gerais, o significado é basicamente formado por estas duas perspectivas, mas com o realce de uma delas.

Não foram encontrados na literatura estudos que relacionassem as variáveis "julgamento e significado de produto" e "percepção do relacionamento" na perspectiva dos clientes, o que constitui uma lacuna na literatura das áreas de Marketing e Comportamento do Consumidor.

Destarte, o principal objetivo deste trabalho, de cunho quantitativo, foi identificar as relações entre os construtos "julgamento e significado de produtos" e o construto "percepção do relacionamento", no caso do smartphone da Apple, o iPhone. Ademais, identificou-se o tipo de julgamento e o significado atribuído pelos clientes da Apple ao iPhone e a percepção 
que estes clientes têm de seu relacionamento com a marca.

Este estudo contribui ao explorar as relações entre duas variáveis que influenciam sobremaneira o desenho de estratégias e ações de marketing e de maneira prática, haja vista que a Administração é uma ciência essencialmente aplicada, para a Apple ou outras fabricantes de smartphones, os resultados podem ser utilizados como diagnóstico para auxiliar os gestores em suas estratégias de promoção de produtos e fidelização de clientes.

\section{REFERENCIAL TEÓRICO}

Esta seção apresentará a síntese da revisão da literatura das duas variáveis importantes à consecução da pesquisa, quais sejam, o julgamento e significado de produto e o marketing de relacionamento.

\subsection{Julgamento e Significado de Produto}

Epstein (1994) assume a existência de dois modos, paralelos e interativos, de processamento de informações para tomada de decisões relativas a compras: um sistema racional cognitivo e um sistema experiencial emocionalmente dirigido. Assim, entender a maneira pela qual os consumidores julgam produtos e tomam decisões quanto à aquisição deles são alguns dos fatores essenciais para compreender o comportamento do consumidor no processo de escolha de produtos. Nesse enredo, Levy (1959) argumenta que empresas não vendem só produtos, mas também símbolos e significados a eles associados que se tornam parte das identidades individuais dos consumidores. Por isso, muitas pessoas dizem identificarem-se com certas marcas e produtos.

De acordo com Allen (2001), a atribuição de significado a um produto baseia-se no tipo de julgamento utilizado pelo consumidor, considerando componentes racionais (atributos específicos de utilidade) e emocionais (intuitivos e holísticos), e influencia sua escolha. Fournier (1991) e Allen (1997) ressaltam que o significado é basicamente formado por estas duas perspectivas simultaneamente, mas com o realce de uma delas. Assim, o significado pode ser percebido de maneira objetiva, por meio de critérios tangíveis e características do objeto e, por outro lado, na perspectiva subjetiva ou simbólica, o significado é associado a experiências e símbolos.

No Modelo de Duas Rotas proposto por Allen (2001), o autor investiga a coexistência de duas possibilidades de avaliação dos atributos do produto ou serviço pelo consumidor. $\mathrm{Na}$ primeira rota, nomeada de direta, os atributos abstratos e subjetivos prevalecem. Já na 
Marketing de relacionamento com a Apple: o papel do julgamento e significado de produto na escolha do iPhone

segunda rota, chamada de indireta, predomina uma análise racional de atributos concretos, tangíveis e objetivos. Esse modelo diz respeito à influência direta ou indireta dos valores humanos no processo de avaliação. Na primeira rota, há influência direta dos valores no significado a ser atribuído ao produto, e na segunda rota, indireta.

No que tange aos tipos de julgamento, Allen (2001) propõe duas dimensões que antecedem a atribuição de significado, a saber, o julgamento passo-a-passo ou racional e o julgamento afetivo ou emocional. O primeiro é baseado na tangibilidade das características do produto e em suas funções. Mittal (1988) o nomeia de processamento informacional e o baseia na avaliação dos atributos tangíveis e funções utilitárias de um determinado produto. Esse modo de julgamento está vinculado a um entendimento sistemático e lógico do produto, entendendo que os atributos tangíveis são avaliados e comparados no processo decisório e, de forma geral, não dependem de experiências anteriores com os objetos (ALLEN, 1997).

O segundo tipo de julgamento, o afetivo, está relacionado a uma afeição imediata e de alta intensidade pelo produto, o que faz com que o julgamento seja conduzido por um estado emocional que leva em consideração o produto como um todo, ou seja, além das suas características tangíveis (ALLEN, 2001). Nesse caso, o indivíduo escolhe de forma mais rápida, subjetiva e intensa, buscando menos informações acerca do objeto e realizando menos comparações (ALLEN, 2000; 2001). O julgamento passo-a-passo e o afetivo precedem, respectivamente, a atribuição de significado utilitário e simbólico para determinado produto (ALLEN, 2000; 2001).

No que diz respeito ao significado utilitário, os atributos tangíveis do objeto são levados em consideração. Esse significado "é objetivo e está baseado em atributos tangíveis do produto, ou seja, relaciona-se à sua utilidade, conveniência, eficiência ou mesmo ao seu valor como moeda de troca" (NEPOMUCENO; TORRES, 2005, p.423). Quanto ao significado simbólico, ele pode ser subjetivo, baseado em experiências e dependente de associações simbólicas (ALFINITO; NEPOMUCENO; TORRES, 2012). Ao contrário do significado utilitário, o subjetivo advém dos elementos intangíveis e externos do produto. Trata-se de um tipo de significado que se origina de um conjunto de experiências baseado em aspectos sociais, ou seja, a cultura a qual a pessoa se insere, e elementos individuais intrínsecos do consumidor (ALLEN, 2000; 2001).

Os significados variam entre sociedades e culturas de forma que o mesmo objeto pode possuir compreensões distintas dependendo do seu contexto. Diante dessa análise subjetiva, o julgamento afetivo fornece as "ferramentas" essenciais para a consolidação desse significado. 
Mittal (1988) defende que no processo de julgamento, as pessoas inconscientemente se imaginam utilizando tal objeto e levam em consideração a aprovação social e o quanto a marca os representa.

Ainda relacionado ao significado de produto, Richins (1994) sustenta que o significado pode ter duas naturezas: pública e privada. A pública, segundo o autor, é constituída basicamente dos significados subjetivos atribuídos pelos não possuidores do mesmo, ou seja, como as pessoas da sociedade o percebem de forma holística. Embora observadores externos possam divergir quanto a sua percepção de determinado objeto, a sociedade no geral ou seus subgrupos tendem a concordar em alguns aspectos do significado atribuído ao bem. Trata-se de um fenômeno compartilhado. Já o significado privado, na visão do autor, está vinculado às percepções particulares do indivíduo em relação ao produto. É fruto das experiências particulares somadas à internalização do significado público. Diferentemente do significado público, constitui-se em um fenômeno individual, possibilitando ao cliente atribuir significados com bases em compras anteriores, como também pela influência do grupo ou sociedade os quais está inserido (RICHINS, 1994).

Quanto às medidas de julgamento e significado, Nepomuceno e Torres (2005) demonstraram uma limitação na medida original desenvolvida por Allen (2001) e validada na Nova Zelândia. Os resultados de Nepomuceno e Torres (2005) validaram somente duas das quatro dimensões do construto proposto por Allen (2001), a saber: dois tipos de julgamento de produto e duas perspectivas de significado, promovendo uma possível confusão conceitual ao ser aplicada em diferentes culturas, como ocorreu no caso brasileiro.

Assim, Nepomuceno, Porto e Rodrigues (2006) analisaram os avanços teóricos das pesquisas sobre comportamento do consumidor que utiliza a abordagem da cognição social no contexto brasileiro, para explicar o porquê e como se avaliam os atos de consumo. Os autores utilizaram como foco a relação de dependência entre os valores humanos e o significado proposto por Allen e Ng (1999) e a relação de interdependência das variáveis de julgamento e significado de produto proposto por Allen no ano de 2001 e concluíram que o modelo de duas rotas necessitava de adaptações visando melhorar sua aplicabilidade no contexto do Brasil.

A partir desta premissa, Alfinito et al (2012) validaram um modelo com as quatro dimensões, que suprisse tal lacuna na literatura e fosse adaptado ao contexto brasileiro. A escala final possui 20 itens que foram distribuídos nas quatro dimensões, a saber: o julgamento passo-a-passo, o julgamento afetivo, o significado utilitário e o significado 
Marketing de relacionamento com a Apple: o papel do julgamento e significado de produto na escolha do iPhone

simbólico.

Por fim, foi realizada uma revisão da produção nacional acerca do tema julgamento e significado de produto no período de 2009 - 2013 em 45 periódicos científicos da área de administração classificados com menção superior ou igual a B2 pelo sistema Qualis da CAPES (Coordenação de Aperfeiçoamento de pessoal de Nível Superior). Os resultados mostraram uma produção de caráter bastante incipiente com apenas 3 artigos. Dois deles provenientes de pesquisas qualitativas e um de pesquisa multimétodo (qualitativo e quantitativo). Quanto às instituições de origem dos autores, há uma predominância de pesquisadores de Brasília, vinculados à Universidade de Brasília.

Os três estudos são teórico-empíricos sendo uma validação de escala e dois outros que analisaram as influências culturais no julgamento e significado de produto aplicável aos consumidores brasileiros. Especificamente, o estudo de Alfinito e Torres (2012) que analisaram a escolha do consumidor baseando-se não apenas nos valores humanos (modelo de duas rotas de Allen (2001), como também no construto de axiomas sociais, propondo um modelo de influência cultural no consumo. Ademais, Mendes, Nascimento, Coutinho, Souza Filho e Freires (2011) avaliaram a influência dos valores humanos e do julgamento e significado de serviços na avaliação de atributos de serviços postais utilizando uma adaptação da escala de julgamento e significado de produto proposta por Nepomuceno e Torres (2005). Em suma, o baixo número de artigos encontrados demostra uma lacuna na literatura que se traduz em um convite a mais pesquisas.

\subsection{Marketing de Relacionamento (CRM)}

É fundamental considerar, nos estudos organizacionais, a perspectiva da competitividade. Junto com a globalização e as novas tecnologias, a competitividade é imperativa resumindo, em sua essência, a busca incessante das organizações por alternativas de diferenciação competitiva. Para Mishra e Mishra (2009), o marketing de relacionamento (ou CRM, do inglês Customer Relationship Management) ajuda as empresas a gerenciar de maneira efetiva as interações com os consumidores para manter a competitividade.

Segundo Porter (1991), a vantagem competitiva é o resultado da capacidade da organização de realizar eficientemente o conjunto de atividades necessárias para obter um custo menor que o dos concorrentes ou de organizar tais atividades de forma única capaz de gerar um valor diferenciado para os clientes. Kumar, Jones, Venkatesan e Leone (2011) investigaram se orientação ao mercado é de fato fonte de vantagem competitiva sustentável e 
descobriram um efeito positivo da orientação para o mercado sobre o desempenho do negócio tanto a curto quanto a longo prazo. O estudo realizado por Mishra e Mishra (2009) mostrou que à medida que mais organizações percebem a importância de tornar-se centrada no cliente na era competitiva atual, mais elas adotam o CRM como estratégia central de negócio, levando-os à conclusão de que o CRM pode ajudar as organizações a gerenciar suas interações com os clientes de forma mais eficaz, a fim de manter a competitividade.

Visando, então, à prosperidade das organizações e à otimização de sua capacidade de se reinventar e competir, os relacionamentos entre organizações e clientes adquirem conotação especial e o CRM, englobando aspectos da satisfação e da lealdade de clientes e, mormente, a oferta constante de experiências únicas e encantadoras a eles, apresenta-se como diferencial profícuo quando a questão é competitividade (DEMO, 2014).

Conforme Grönroos (1994), Sheth e Parvatiyar (2002) e Payne (2006), marketing de relacionamento representa uma mudança de paradigma dos conceitos de marketing defendendo uma mudança na orientação do marketing para a conquista de clientes para o foco na retenção ou lealdade de clientes. Tal mudança reflete a passagem do marketing transacional para o de relacionamento.

Na visão de Payne (2006), o CRM provê oportunidades para utilizar informações, conhecer melhor os clientes, oferecer valor por meio de ofertas customizadas e desenvolver relacionamentos duradouros. É então necessário que a empresa possua processos, operações e pessoas integradas para que a essência do marketing possa ser a filosofia que norteia todo o negócio. Essa visão confirma a ideia holística do marketing de relacionamento, em que há integração entre todas as partes da organização.

De acordo com Reichheld e Sasser Jr. (1990, p.105), à medida que o relacionamento do cliente com a empresa estende-se, os lucros crescem. Eles afirmam que "as empresas podem aumentar seus lucros em quase 100\% retendo apenas mais $5 \%$ de seus clientes". Os autores defendem ainda que os clientes geram lucros maiores a cada ano a mais que eles permanecem com a empresa. Por causa do grande aumento da concorrência e do constante aprimoramento tecnológico, os clientes possuem um leque muito maior de escolhas do que possuíam anteriormente. Destarte, reter os clientes, desenvolver um relacionamento com eles e satisfazê-los continuamente podem ser consideradas as bases de uma trajetória bemsucedida na maioria das organizações. "Clientes a longo prazo compram mais, tomam menos tempo da empresa, são menos sensíveis ao preço e trazem novos clientes, além de não possuírem custo de aquisição" (REICHHELD, 1996, p. 02). 
Marketing de relacionamento com a Apple: o papel do julgamento e significado de produto na escolha do iPhone

Com seu surgimento na década de 1990, o CRM rapidamente tornou-se uma proposta de patente relevância. No entanto, a compreensão do que o CRM significa ainda se faz limitada. Muitas empresas não entendem o CRM como um sinônimo do marketing de relacionamento e o encaram como uma solução tecnológica, confundindo a gestão do relacionamento com o cliente com os sistemas de apoio para implementação do CRM. Relativamente a esta controvérsia, Bygstad (2003) conduziu um estudo de caso longitudinal de 6 anos em uma empresa que implementou o CRM tanto como um princípio de marketing quanto como um sistema de informação. $\mathrm{O}$ autor concluiu que projetos de CRM devem ser tratados como desafios complexos e sob uma perspectiva gerencial, necessitando de controle rigoroso e da aplicação de técnicas de gestão da mudança, com foco nos processos de marketing e na qualidade das informações.

Na visão de Payne (2006), é certo que o CRM consiste em uma abordagem estratégica holística para gerenciar o relacionamento com clientes a fim de criar valor para o acionista. Ele defende que o CRM provê mais oportunidades para o uso de dados e informações no sentido de entender o cliente e implementar melhor as estratégias de marketing de relacionamento, mas isso não o limita a um sistema de informação ou a uma ferramenta tecnológica. $\mathrm{O}$ autor ressalta que a importância em definir o CRM corretamente não é apenas um preciosismo semântico. Tal definição impacta significativamente a maneira como o CRM é entendido, implantado e praticado nas organizações. Nesse contexto, Payne (2006) destaca que o CRM, para ser bem-sucedido, precisa estar imbuído de visão estratégica para criar valor ao acionista através do desenvolvimento de relacionamentos com clientes estratégicos, unindo o potencial da tecnologia da informação (TI) às estratégias de marketing de relacionamento que resultarão no estabelecimento de relacionamentos lucrativos de longo prazo.

Zablah, Bellenger e Johnston (2004) concordam que a literatura CRM ainda é inconsistente e altamente fragmentada devido à falta de uma conceituação comum, e assim propõem uma definição de CRM como um "processo contínuo que envolve o desenvolvimento e alavancagem de inteligência de mercado com o objetivo de construir e manter um portfólio de maximização do lucro de relacionamento com os cliente" (p. 475). Essa ideia converge com o quadro conceitual apresentado por Campbell (2003) quanto aos processos internos envolvidos na competência de criar conhecimento sobre os clientes, composta por quatro componentes: processo de informação do cliente; interface entre marketing e TI (tecnologia da informação) de interface; envolvimento da alta administração, 
e sistemas de avaliação e recompensa aos empregados.

A produção recente sobre CRM em artigos internacionais traz estudos como o de Huang e Xiong (2010), constatando que o CRM atingiu uma maturidade estratégica e influencia todo o ciclo de vida de um produto e não apenas etapas de pré ou pós-venda. Ainda sobre a ampliação da influência do CRM, Ernst, Hoyer, Krafft e Krieger (2011) argumentam que o potencial do CRM tem sido investigado somente no caso de produtos existentes, devendo ser considerado também no desenvolvimento de novos produtos, uma vez que seus estudos evidenciaram que a gestão de relacionamento com o cliente tem uma correlação positiva com o desempenho e o sucesso de novos produtos.

Considerando, ainda, que a cultura corporativa não tem sido suficientemente estudada no marketing de relacionamento, Iglesias, Sauquet e Montaña (2011) apresentaram um modelo da cultura corporativa de uma empresa orientada para o CRM. Os resultados da pesquisa demonstraram que os dois fatores primordiais necessários para sua efetivação são a "orientação ao cliente" e o "alto grau de cuidado para com os funcionários". Além disso, outros seis valores compartilhados (confiança, envolvimento, trabalho em equipe, inovação, flexibilidade e orientação para resultados) também facilitariam o desenvolvimento da orientação para o marketing de relacionamento.

Quanto às revisões da literatura sobre CRM, foi considerado como marco o primeiro artigo de Ngai (2005) que concluiu pelo vigor da pesquisa acadêmica sobre marketing de relacionamento, interrogou sobre a baixa percentagem de trabalhos relacionados à privacidade em CRM, propondo que o setor continuaria a apresentar um crescimento significante nos próximos anos. As revisões mais recentes de Ngai, Xiu e Chayu (2009), Wahlberg et al. (2009), Demo et al (2011), Gupta e Sahu (2012), Benouakrim e El Kandoussi (2013), Sojan, Raphy e Thomas (2014) e Faria et al. (2014) confirmaram as expectativas de Ngai (2005) atestando a maturidade no campo da pesquisa científica em CRM.

Outras conclusões destes estudos apontam a predominância de pesquisa de CRM em grandes empresas em detrimento de médias e pequenas empresas, a dissociação do conceito de CRM à mera ferramenta tecnológica bem como de sua implementação como responsabilidade da área de tecnologia da informação e, ainda, a prevalência de estudos com foco no mercado consumidor (B2C) no Brasil enquanto que os estudos internacionais privilegiam o mercado corporativo (B2B). Ademais, parece haver carência de medidas específicas de CRM para o mercado B2C.

No que tange a medidas de CRM, foram encontrados alguns estudos com validação de 
Marketing de relacionamento com a Apple: o papel do julgamento e significado de produto na escolha do iPhone

escala baseados principalmente nos trabalhos de Wilson e Vlosky (1997), Sin, Tse e Yim (2005), Agariya e Singh (2012a) e Rozzett e Demo (2010a ; 2010b , 2011). Wilson e Vlosky (1997) desenvolveram uma escala de CRM para o mercado corporativo (B2B) e Viana, Cunha Jr e Slongo (2005) adaptaram-na para o setor industrial no Brasil. Sin, Tse e Yim (2005) validaram uma escala para medir as dimensões de CRM praticadas pelas empresas do setor de serviços financeiros de Hong Kong. A partir daí, Soch e Sandhu (2008) desenvolveram uma escala de CRM aplicada às indústrias manufatureiras na Índia, Wang e Feng (2008) validaram uma escala de CRM para o setor de serviços na China e Öztaysi, Sezgin e Özok (2011) propuseram um instrumento para avaliar os processos internos de CRM na Turquia.

Recentemente, Agariya e Singh (2012a , 2012b , 2013) desenvolveram um indicador de CRM para os setores bancário e de seguros e uma escala de CRM para os clientes de hospitais públicos na Índia, e Zulkifli e Tahir (2012) validaram uma escala de práticas de CRM especificamente para clientes de bancos. Finalmente, Rozzett e Demo (2010a; 2010b; 2011) conduziram três estudos no Brasil e um nos Estados Unidos (DEMO; ROZZETT, 2013) para desenvolver e validar uma escala para o mercado consumidor (B2C) com o objetivo de avaliar a percepção dos clientes quanto aos seus relacionamentos com as empresas em geral.

Foi também realizada uma revisão da produção nacional acerca do CRM no período de 2009 - 2013 em 45 periódicos científicos da área de administração classificados com menção superior ou igual a B2 pelo sistema Qualis da CAPES. Os resultados evidenciaram uma produção de 35 artigos em 21 dos periódicos selecionados. Os anos de 2009 e 2012 apresentaram maior registro de artigos correspondendo a mais de $63 \%$ da produção dos últimos 5 anos. A maioria absoluta desses artigos tratava-se de estudos teórico-empíricos, quantitativos e focavam em empresas privadas. Esta revisão mostrou um leve declínio na produção acerca do tema nos últimos três anos, o que pode sinalizar uma possível consolidação das pesquisas sobre o tema no Brasil, não obstante, ainda há carência de estudos de natureza multimétodo para melhor compreender o fenômeno e também da realização de pesquisas no setor privado e no terceiro setor.

Por fim, no que tange à possibilidade de relações entre o julgamento e significado atribuído a produtos e a percepção de relacionamento com as marcas dos produtos, entendese que a maneira pelo qual os consumidores processam seu julgamento e atribuem significados a produtos afetam suas tomadas de decisão quanto à compra e à intenção de se 
permanecer fiel à uma organização ou marca (RICHINS, 1994). Dessarte, o relacionamento dos consumidores com marcas e empresas deve ser influenciado pelo julgamento e significado que eles atribuem a produtos comercializados pela empresa.

\section{MÉTODO}

A presente pesquisa pode ser classificada quanto aos fins como descritiva, quanto aos meios como survey (de campo), de natureza quantitativa e de corte transversal. No que diz respeito à marca estudada, trata-se da empresa multinacional norte-americana Apple Inc que foi fundada em 1976 nos Estados Unidos da América. É uma empresa do ramo tecnológico e amplamente conhecida por antecipar tendências e conquistar seus clientes com seus produtos de alta qualidade. A empresa apresentou um crescimento acelerado no mercado e alcançou a participação liderante em diversos segmentos do mercado. No ano de 2013, a Apple ultrapassou a Coca-Cola e alcançou a liderança como a marca mais valiosa do mundo (INTERBRAND, 2013). Soma-se ainda que ela foi eleita a marca mais admirada do Brasil no ano de 2013 (CARTA CAPITAL, 2013) e no mundo nos mesmos anos (FORTUNE, 2013). Muito além das vendas, a empresa preocupa-se bastante com seus clientes e, por isso, a Apple foi campeã em lealdade de clientes de smartphones, segundo o ranking elaborado pela Brand Keys em 2014 (BRAND KEYS, 2014). Por esses motivos, escolheu-se pesquisar clientes desta empresa campeã de lealdade e admiração.

Como o objetivo do presente estudo foi a obtenção de informações sobre o comportamento dos usuários do smartphone iPhone da marca Apple, eles corresponderam à população da pesquisa. Como a população-alvo tende ao infinito, foi possível utilizar amostra não probabilística por conveniência (COCHRAN, 2007), utilizando-se coleta on-line por meio da ferramenta TypeForm. A coleta de dados foi realizada nos meses de agosto e setembro de 2013. Hair et al (2009) apontaram uma série de vantagens do uso da internet em coleta de dados como o baixo custo, a agilidade e a flexibilidade. As explicações sobre o procedimento das respostas foram devidamente indicadas no termo de consentimento com o intuito de evitar a perda de muitos questionários por preenchimentos indevidos. $\mathrm{O}$ instrumento elaborado na ferramenta TypeForm foi disponibilizado em redes sociais e contatos de e-mail e utilizando-se a técnica bola de neve, uma das mais comuns para amostras não-probabilísticas por conveniência, onde, a partir das ligações entre os membros da população, parte-se de alguns indivíduos que respondem ao questionário e o encaminham posteriormente a suas redes de contatos (SALGANIK; HECKATHORN, 2004).

REAd | Porto Alegre - Edição 80 - N 1 - janeiro/abril 2015 - p. 170-199 
Marketing de relacionamento com a Apple: o papel do julgamento e significado de produto na escolha do iPhone

Quanto ao tamanho da amostra, o software GPower indicou um alvo inicial de 129 respondentes, considerando efeito esperado médio, taxa de erro de 5\%, 4 graus de liberdade (correspondentes à quantidade de fatores da variável independente) e poder estatístico de 95\% para a técnica de análise de dados escolhida, a saber, regressão múltipla linear. Foram respondidos 251 questionários.

O processo de tratamento dos dados iniciou-se com a análise de dados por meio da distribuição de frequências (média, desvio padrão, variância, mínimo e máximo), e constatouse que os dados estavam dentro dos valores mínimo e máximo da escala de avaliação. $\mathrm{O}$ tratamento em relação aos dados faltantes foi realizado por meio do método Listwise, porque segundo Hair et al (2009) e Tabachnick e Fidell (2007) é o tratamento mais recomendável ao retirar da amostra os sujeitos que deixaram algum item em branco. Assim, 50 respondentes foram excluídos da amostra. Em seguida, fez-se a análise de verificação de outliers, que podem ser entendidos como aqueles valores que se afastam muito dos demais e da média (HAIR et al, 2009), por meio da distância denominada Mahalonobis (D2=18,467; $\mathrm{p}<0,001$ ), conforme recomendado por Tabachnick e Fidell (2007) e nenhum outlier foi encontrado.

Além disso, as seguintes suposições para regressão (HAIR et al, 2009; FIELD, 2009), foram analisadas por meio de gráficos de resíduos, gráficos de probabilidade normal e testes estatísticos; linearidade do fenômeno, variância constante dos termos de erro (homoscedasticidade), independência dos termos de erro e normalidade da distribuição dos termos de erro. Por fim, as análises de multicolinearidade e singularidade não apresentaram problemas para a amostra pesquisada.

A amostra final contou com 201 sujeitos, ainda bastante satisfatória para as análises estatísticas. A maioria absoluta de $94 \%$ foram usuários do iPhone no Brasil e o restante $(6 \%)$ de usuários em outros países (Portugal, Inglaterra, EUA, Argentina e Uruguai). No que se refere à idade, a amostra foi predominantemente de jovens de 18 a 22 anos (61\%), com nível superior completo $(48,8 \%)$ e cujo relacionamento com a marca datava entre 1 e 5 anos (57\%).

No que concerne ao instrumento de pesquisa, ele foi composto, além dos dados sociodemográficos para caracterizar a amostra, por 2 escalas de mensuração, validadas cientificamente e com bons parâmetros psicométricos. Essas escalas utilizadas foram a Escala de Julgamento e Significado de Produto, construída e validada por Alfinito, Nepomuceno e Torres (2012), e a Escala de Relacionamento com Clientes desenvolvida e validada por Demo e Rozzett (2013).

A escala de Julgamento e Significado possui 20 itens, distribuídos em quatro fatores, REAd | Porto Alegre - Edição 80 - N 1 - janeiro/abril 2015 - p. 170-199 
dois fatores estão relacionados aos tipos de julgamento (passo-a-passo e afetivo), enquanto os outros dois estão relacionados aos tipos de significados (utilitário e simbólico). Tal escala tem composição tipo Likert de 7 pontos, que mensura a intensidade com que a pessoa concorda ou discorda de determinada afirmação e possui uma confiabilidade por fator que varia entre 0,74 e 0,81 ( $\alpha$ de Cronbach). Já a Escala de Relacionamento com o Cliente é unifatorial composta por 14 itens e confiabilidade de 0,92 ( $\alpha$ de Cronbach). Também é avaliada por meio de uma escala de concordância tipo Likert de 5 pontos. O Quadro 1 apresenta as variáveis do estudo que são provenientes dos itens e dos fatores aos quais se remetem das duas escalas já validadas e que compuseram o instrumento de coleta de dados desta pesquisa, sendo CRMmarketing de relacionamento, JA-julgamento afetivo ou emocional, JP-julgamento racional ou passo-a-passo, SS-significado simbólico e SU-significado utilitário ou objetivo.

Quadro 1 - Itens do instrumento de aplicação e seus respectivos fatores

\begin{tabular}{|c|c|c|c|c|c|}
\hline Item & Questão & Variável & Item & Questão & Variável \\
\hline 1 & $\begin{array}{l}\text { Fui racional ao comprar o } \\
\text { iPhone. }\end{array}$ & JP & 18 & $\begin{array}{l}\text { Seleciono o smartphone em } \\
\text { função do meu sentimento em } \\
\text { relação a ele. }\end{array}$ & JA \\
\hline 2 & $\begin{array}{l}\text { Escolhi o iPhone, pois posso } \\
\text { exibir com orgulho. }\end{array}$ & SS & 19 & $\begin{array}{l}\text { Seleciono o smartphone de } \\
\text { uso mais rápido. }\end{array}$ & SU \\
\hline 3 & $\begin{array}{l}\text { Escolhi o iPhone por ser } \\
\text { compatível com o que penso } \\
\text { sobre mim mesmo. }\end{array}$ & JA & 20 & $\begin{array}{l}\text { Penso bem antes de comprar } \\
\text { um smartphone. }\end{array}$ & JP \\
\hline 4 & $\begin{array}{l}\text { Escolhi o iPhone porque está } \\
\text { na moda. }\end{array}$ & SS & 21 & $\begin{array}{l}\text { A Apple merece minha } \\
\text { confiança. }\end{array}$ & CRM \\
\hline 5 & $\begin{array}{l}\text { Escolhi o iPhone por ser um } \\
\text { produto sensorialmente } \\
\text { agradável (ex: olfato, visão, } \\
\text { etc.). }\end{array}$ & JA & 22 & $\begin{array}{l}\text { Eu recomendo a Apple a } \\
\text { amigos e familiares. }\end{array}$ & CRM \\
\hline 6 & $\begin{array}{l}\text { Selecionei o iPhone porque } \\
\text { posso encontrar mais } \\
\text { facilmente para comprar. }\end{array}$ & SU & 23 & $\begin{array}{l}\text { A Apple me trata como um } \\
\text { cliente importante. }\end{array}$ & CRM \\
\hline 7 & $\begin{array}{l}\text { Escolhi o iPhone por ser um } \\
\text { produto reconhecidamente } \\
\text { caro. }\end{array}$ & SS & 24 & $\begin{array}{l}\text { Minhas experiências de } \\
\text { compra com a Apple superam } \\
\text { minhas expectativas. }\end{array}$ & CRM \\
\hline 8 & $\begin{array}{l}\text { Considerei os prós e contras } \\
\text { antes de comprar o iPhone. }\end{array}$ & JP & 25 & Identifico-me com a Apple. & CRM \\
\hline 9 & $\begin{array}{l}\text { Escolhi o iPhone porque me } \\
\text { deixa de bom humor ao usá-lo. }\end{array}$ & JA & 26 & $\begin{array}{l}\text { A Apple me trata com } \\
\text { respeito. }\end{array}$ & CRM \\
\hline 10 & $\begin{array}{l}\text { Selecionei o iPhone por ser } \\
\text { um produto de uso mais fácil. }\end{array}$ & SU & 27 & $\begin{array}{l}\text { A Apple me oferece } \\
\text { atendimento personalizado. }\end{array}$ & CRM \\
\hline 11 & $\begin{array}{l}\text { Considero importante comprar } \\
\text { uma marca reconhecida } \\
\text { socialmente (Apple). }\end{array}$ & SS & 28 & $\begin{array}{l}\text { Os smartphones vendidos pela } \\
\text { Apple têm bom valor (os } \\
\text { benefícios excedem os custos). }\end{array}$ & CRM \\
\hline 12 & $\begin{array}{l}\text { Controlo minha impulsividade } \\
\text { ao comprar um iPhone. }\end{array}$ & JP & 29 & $\begin{array}{l}\text { A Apple é eficiente na solução } \\
\text { de problemas. }\end{array}$ & CRM \\
\hline 13 & $\begin{array}{l}\text { Dou mais importância à beleza } \\
\text { do iPhone. }\end{array}$ & SS & 30 & $\begin{array}{l}\text { A Apple procura conhecer } \\
\text { minhas preferências. }\end{array}$ & CRM \\
\hline
\end{tabular}

REAd | Porto Alegre - Edição 80 - N 1 - janeiro/abril 2015 - p. 170-199 
Marketing de relacionamento com a Apple: o papel do julgamento e significado de produto na escolha do iPhone

\begin{tabular}{|c|l|c|c|l|c|}
14 & $\begin{array}{l}\text { Seleciono smartphones de } \\
\text { forma cuidadosa. }\end{array}$ & JP & 31 & $\begin{array}{l}\text { A Apple recompensa minha } \\
\text { fidelidade. }\end{array}$ & CRM \\
\hline 15 & $\begin{array}{l}\text { Prefiro o iPhone porque } \\
\text { demonstra poder sobre as } \\
\text { outras pessoas. }\end{array}$ & SS & 32 & $\begin{array}{l}\text { Estou disposto a comprar } \\
\text { outros produtos/serviços da } \\
\text { Apple. }\end{array}$ & CRM \\
\hline 16 & $\begin{array}{l}\text { Prefiro o iPhone, pois reflete } \\
\text { meu jeito de ser. }\end{array}$ & JA & 33 & $\begin{array}{l}\text { A Apple possui boas } \\
\text { instalações (físicas e virtuais). }\end{array}$ & CRM \\
\hline 17 & $\begin{array}{l}\text { Procuro o máximo de } \\
\text { informações sobre o } \\
\text { smartphone que vou comprar. }\end{array}$ & JP & 34 & $\begin{array}{l}\text { Os smartphones vendidos pela } \\
\text { Apple são de alta qualidade. }\end{array}$ & CRM \\
\hline
\end{tabular}

Fonte: dados da pesquisa

Quanto à análise dos dados, primeiro foram realizadas análises estatísticas descritivas a fim de identificar o tipo de julgamento que os clientes do aparelho fazem desse produto, o significado atribuído ao iPhone pelos usuários e identificar a percepção que os portadores do produto possuem quanto ao seu relacionamento com a Apple. Em seguida, foram realizadas análises de regressão múltipla linear, tendo como variáveis independente as quatro dimensões do construto "julgamento e significado de produtos" (julgamento afetivo, julgamento fragmentado, significado simbólico e significado utilitário) e variável dependente o construto "percepção do relacionamento com a marca".

A regressão múltipla, segundo Tabachnick e Fidell (2007) possibilita a avaliação do relacionamento de uma variável dependente com diversas variáveis independentes, obtendo como resultado uma equação linear de predição da variável dependente. A regressão múltipla apresenta-se como um modelo mais realista porque a previsão de qualquer situação quase sempre depende de diversos fatores, não de somente um, sendo uma técnica adequada para estimar relações entre variáveis (HAIR et al, 2009).

A qualidade de um modelo de regressão múltipla linear pode ser observada por meio da inspeção de algumas variáveis, quais sejam, o coeficiente de determinação $\left(R^{2}\right)$ : trata-se do parâmetro mais indicado para interpretar resultados obtidos em uma regressão e apresenta a medida da proporção da variância da variável dependente em torno da sua média que é explicada pelas variáveis independentes (HAIR et al., 2009); o coeficiente de regressão padronizado $(\beta)$ : permite comparação direta entre coeficientes e seus poderes relativos de explicação da variável dependente e representa a magnitude e a direção do relacionamento entre cada preditor e a variável dependente (HAIR et al., 2009); e a significância estatística dos resultados onde um valor estatisticamente significante deve ser inferior a 0,05 ou $5 \%$, ou seja, $\mathrm{p}<0,05$ (FIELD,2009).

\section{RESULTADOS E DISCUSSÃO}

REAd | Porto Alegre - Edição 80 - Nº 1 - janeiro/abril 2015 - p. 170-199 
Em primeira instância, identificou-se o tipo de julgamento feito pelos clientes do produto iPhone. A média das respostas para o julgamento passo-a-passo foi de 5,48 com desvio padrão de 1,11 , demonstrando a tendência central das respostas levantadas. $O$ julgamento afetivo apresentou média de 4,52 com desvio padrão de 1,30, representando também uma maior concentração dos respondentes em valores próximos à média.

Ambos os tipos de julgamento apresentaram percepção positiva (médias acima de 3,0) por parte dos entrevistados, o que pode ser explicado pela avaliação do produto como um todo, ou seja, sob influência dos fatores tangíveis como também dos intangíveis. Allen (2001), em seu modelo de duas rotas, defende a coexistência de duas dimensões que antecedem a atribuição de significado, a saber: o julgamento passo-a-passo e o julgamento afetivo. Esse modelo pôde ser comprovado com os resultados. E, com maior média, o julgamento passo-a-passo possui maior influência no processo de escolha dos consumidores de iPhone pesquisados.

Quanto ao total de respostas para julgamento passo-a-passo, a maioria dos respondentes apresentou os valores 6 e 7, o que indica influência dos aspectos tangíveis do iPhone e suas funções utilitárias no processo de tomada de decisão. Já para o julgamento afetivo, a maioria escolheu os valores 4 e 5, indicando menor afeição imediata e de alta intensidade pelo produto em comparação à força dos elementos funcionais do mesmo produto, ou seja, os sujeitos da amostra tendem a prezar substancialmente pelos elementos utilitários do produto comparando-se com os intangíveis. Outrossim, como já foi levantado, os dois fatores se fazem presentes no julgamento do produto, como também corroborado por Alfinito et al (2012).

Em suma, os resultados para esta variável mostraram que, diante das perguntas estabelecidas, no momento de compra e/ou de escolha do smartphone, parece haver um envolvimento predominantemente racional do indivíduo com o produto. Esse julgamento passo-a-passo, como já foi dito anteriormente, está vinculado a um entendimento sistemático e lógico do produto (ALLEN,1999). As Tabelas 1 e 2 ilustram as estatísticas descritivas quanto ao julgamento passo-a-passo e afetivo, respectivamente.

Tabela 1 - Estatísticas descritivas para Julgamento Passo-a-Passo

\begin{tabular}{clcccccc}
\hline \multicolumn{1}{c}{ Item } & Mínimo & Máximo & Mediana & Moda & Média & $\begin{array}{c}\text { Desvio } \\
\text { Padrão }\end{array}$ \\
\hline 1 & 1 & 7 & 6 & 7 & 5,93 & 1,400 \\
\hline $\begin{array}{l}\text { Fui racional ao comprar o } \\
\text { iPhone. }\end{array}$ & $\begin{array}{l}\text { Considerei os prós e contras } \\
\text { antes de comprar o iPhone. }\end{array}$ & 1 & 7 & 6 & 4 & 5,61 & 1,735 \\
\hline 12 & Controlo minha impulsividade & 1 & 7 & 4 & 4 & 3,98 & 2,100 \\
\hline
\end{tabular}

REAd | Porto Alegre - Edição 80 - N 1 - janeiro/abril 2015 - p. 170-199 
Marketing de relacionamento com a Apple: o papel do julgamento e significado de produto na escolha do iPhone

ao comprar um iPhone.

\begin{tabular}{cccccccc}
\hline 14 & $\begin{array}{l}\text { Seleciono smartphones de } \\
\text { forma cuidadosa. }\end{array}$ & 1 & 7 & 6 & 7 & 5,68 & 1,499 \\
\hline 17 & $\begin{array}{l}\text { Procuro o máximo de } \\
\text { informações sobre o } \\
\text { smartphone que vou comprar. }\end{array}$ & 1 & 7 & 7 & 7 & 5,82 & 1,715 \\
\hline 20 & $\begin{array}{l}\text { Penso bem antes de comprar } \\
\text { um smartphone. }\end{array}$ & 1 & 7 & 7 & 7 & 5,86 & 1,695 \\
\hline
\end{tabular}

Fonte: dados da pesquisa

Tabela 2 - Estatísticas descritivas para Julgamento Afetivo

\begin{tabular}{|c|c|c|c|c|c|c|c|}
\hline & Item & Mínimo & Máximo & Mediana & Moda & Média & $\begin{array}{l}\text { Desvio } \\
\text { Padrão }\end{array}$ \\
\hline 3 & $\begin{array}{l}\text { Escolhi o IPhone por ser } \\
\text { compatível com o que penso } \\
\text { sobre mim mesmo. }\end{array}$ & 1 & 7 & 4 & 4 & 4,27 & 1,905 \\
\hline 5 & $\begin{array}{l}\text { Escolhi o IPhone por ser um } \\
\text { produto sensorialmente } \\
\text { agradável (ex: olfato, visão, etc.). }\end{array}$ & 1 & 7 & 6 & 7 & 5,63 & 1,576 \\
\hline 9 & $\begin{array}{l}\text { Escolhi o IPhone porque me } \\
\text { deixa de bom humor ao usá-lo. }\end{array}$ & 1 & 7 & 5 & 5 & 4,53 & 1,993 \\
\hline 16 & $\begin{array}{l}\text { Prefiro o IPhone, pois reflete } \\
\text { meu jeito de ser. }\end{array}$ & 1 & 7 & 4 & 1 & 3,72 & 2,099 \\
\hline 18 & $\begin{array}{l}\text { Seleciono o smartphone em } \\
\text { função do meu sentimento em } \\
\text { relação a ele. }\end{array}$ & 1 & 7 & 5 & 7 & 4,46 & 2,093 \\
\hline
\end{tabular}

Fonte: dados da pesquisa

Quanto ao significado atribuído pelos clientes ao iPhone, para o significado utilitário, foi encontrada uma média de 4,57 com desvio padrão de 1,09. E para o significado simbólico, obteve-se 2,93 de média com desvio padrão de 1,33. Dessa forma, é possível compreender que os consumidores, após um julgamento predominantemente racional, privilegiam os atributos tangíveis e funcionais do objeto, ou seja, sua utilidade e funcionalidade. Essa conclusão se relaciona ao modelo de duas rotas de Allen (2001) e também ao trabalho de Alfinito et al (2012), pois ambos acharam correlação positiva entre o julgamento passo-apasso e o significado utilitário.

Quanto ao total de respostas para significado simbólico, a maioria apresentou o valor 1, o que indica baixa consideração dos aspectos intangíveis do produto, ou seja, os aspectos que dependem do indivíduo e suas experiências. Por outro lado, o significado utilitário apresentou a maioria das respostas correspondendo aos valores 5, 6 e 7. Isso sinaliza que os usuários pesquisados atribuem maior importância aos atributos funcionais do iPhone, concordando com o resultado obtido para o julgamento passo-a-passo.

Todos os itens relativos ao significado simbólico evidenciaram que os usuários REAd | Porto Alegre - Edição 80 - Nº 1 - janeiro/abril 2015 - p. 170-199 
conferem menos importância aos elementos intangíveis do produto e que são externos ao mesmo, pois suas médias e medianas possuem valor inferior ou igual ao ponto central da escala. Os itens referentes ao significado utilitário apresentaram média superior ao ponto central da escala em duas das três questões. Essa relação, como já levantado anteriormente, pode se vincular à predominância do julgamento passo-a-passo no comportamento do consumidor diante do smartphone.

As Tabelas 3 e 4 ilustram as estatísticas descritivas quanto ao significado simbólico e utilitário, respectivamente.

Tabela 3 - Estatísticas descritivas para Significado Simbólico

\begin{tabular}{clcccccc}
\hline \multicolumn{1}{c}{ Item } & Mínimo & Máximo & Mediana & Moda & Média & $\begin{array}{c}\text { Desvio } \\
\text { Padrão }\end{array}$ \\
\hline 2 & $\begin{array}{l}\text { Escolhi o IPhone, pois posso } \\
\text { exibir com orgulho. }\end{array}$ & 1 & 7 & 3 & 1 & 3,40 & 2,028 \\
\hline 4 & $\begin{array}{l}\text { Escolhi o IPhone porque está } \\
\text { na moda. }\end{array}$ & 1 & 7 & 3 & 1 & 3,08 & 2,004 \\
\hline 7 & $\begin{array}{l}\text { Escolhi o IPhone por ser um } \\
\text { produto reconhecidamente } \\
\text { caro. }\end{array}$ & 1 & 7 & 1 & 1 & 2,10 & 1,676 \\
\hline 11 & $\begin{array}{l}\text { Considero importante comprar } \\
\text { uma marca reconhecida } \\
\text { socialmente (Apple). }\end{array}$ & 1 & 7 & 4 & 1 & 3,83 & 2,036 \\
\hline 13 & $\begin{array}{l}\text { Dou mais importância à } \\
\text { beleza do IPhone. }\end{array}$ & 1 & 7 & 3 & 1 & 3,23 & 1,813 \\
\hline $\begin{array}{l}\text { Prefiro o IPhone porque } \\
\text { demonstra poder sobre as outras } \\
\text { pessoas. }\end{array}$ & 1 & 7 & 1 & 1 & 1,98 & 1,619 \\
\hline
\end{tabular}

Fonte: dados da pesquisa

Tabela 4 - Estatísticas descritivas para Significado Utilitário

\begin{tabular}{clcccccc}
\hline \multicolumn{1}{c}{ Item } & Mínimo & Máximo & Mediana & Moda & Média & $\begin{array}{c}\text { Desvio } \\
\text { Padrão }\end{array}$ \\
\hline 6 & $\begin{array}{l}\text { Selecionei o IPhone porque } \\
\text { posso encontrar mais } \\
\text { facilmente para comprar. }\end{array}$ & 1 & 7 & 2 & 1 & 2,63 & 1,756 \\
\hline 10 & $\begin{array}{l}\text { Selecionei o IPhone por ser } \\
\text { um produto de uso mais } \\
\text { fácil. }\end{array}$ & 1 & 7 & 6 & 7 & 5,54 & 1,649 \\
\hline 19 & $\begin{array}{l}\text { Seleciono o smartphone de } \\
\text { uso mais rápido. }\end{array}$ & 1 & 7 & 6 & 7 & 5,54 & 1,603 \\
\hline
\end{tabular}

Fonte: dados da pesquisa

No que se refere à identificação da percepção do relacionamento com a marca Apple dos usuários do iPhone, a média dessa variável foi de 3,90, com desvio padrão de 0,73 , o que reflete uma percepção moderadamente positiva do relacionamento com a marca Apple considerando a escala de 5 pontos. As medianas, que representam a tendência central das respostas, ou seja, o valor que concentra o maior número de respostas, apresentaram valores

REAd | Porto Alegre - Edição 80 - N 1 - janeiro/abril 2015 - p. 170-199 
Marketing de relacionamento com a Apple: o papel do julgamento e significado de produto na escolha do iPhone

de 3 a 5, que são valores iguais ou superiores ao ponto central da escala e a moda obteve valor igual a 5 .

Destaca-se que não houve percepção dos clientes pesquisados (média inferior ao ponto neutro da escala) no que se refere à recompensa da fidelidade por parte da Apple, sendo o único item com média inferior a 3,0. De fato, não é conhecido nenhum programa de fidelização de clientes da Apple. Com isso, pode-se supor que a fidelização dos clientes está mormente relacionada à qualidade do produto oferecido, item este que apresentou a maior média da escala, evidenciando a importância da alta qualidade do produto para o relacionamento com a marca.

Os itens com melhor avaliação pelos consumidores (médias acima de 4,0) encontram respaldo na literatura de CRM. O item melhor avaliado foi o relativo à alta qualidade do produto, apontado como fundamental no sentido de se estabelecer relacionamentos de longo prazo entre empresa e clientes por Demo e Ponte (2008). Conforme os achados de Rozzet e Demo (2010), são também importantes indicadores de CRM a recomendação de produtos a amigos e familiares, e a intenção de realizar compras de outros produtos da empresa, itens também com alta avaliação na presente pesquisa. Na mesma linha, Demo e Rozzett (2013) destacaram a relevância de os clientes estarem satisfeitos com as instalações físicas (lojas) e virtuais (sites) da empresa, uma vez que sinaliza esforços da organização para prestar um atendimento eficaz, o que foi corroborado neste estudo com os usuários do iPhone pesquisados.

Outro item muito bem avaliado também foi o que diz respeito à confiança na marca que também pode estar relacionada à alta qualidade dos produtos. De acordo com Brei e Rossi (2005) e Demo e Rozzett (2013), a confiança é um importante indicador do relacionamento e é um dos principais pontos-chave no relacionamento com o cliente e tem papel importante na fidelização de clientes. Essa confiança, ainda segundo os autores, tende a se relacionar com a intenção de comprar outros produtos ou serviços da marca e de recomendar o produto a amigos e familiares.

Em se tratando de experiências com a marca, que são momentos essenciais para a fidelização dos clientes, os itens referentes à superação de expectativas, à preferência pelo produto em relação aos concorrentes e ao tratamento como cliente importante pela empresa obtiveram valores positivos mas que não ultrapassaram 4. Considerando o ponto máximo da escala que é 5 , isto significa um importante espaço de melhorias que ainda podem ser implantadas pela Apple. A Tabela 5 sintetiza as estatísticas descritivas para relacionamento 
Gisela Demo \& Morgana Guanabara

com a marca.

Tabela 5 - Estatísticas descritivas para percepção do relacionamento com a Apple

Item

Mínimo Máximo Mediana Moda Média

Desvio

Padrão

\begin{tabular}{|c|c|c|c|c|c|c|c|}
\hline 21 & $\begin{array}{l}\text { A Apple merece minha } \\
\text { confiança. }\end{array}$ & 1 & 5 & 5 & 5 & 4,27 & 0,947 \\
\hline 22 & $\begin{array}{l}\text { Eu recomendo a Apple a } \\
\text { amigos e familiares. }\end{array}$ & 1 & 5 & 5 & 5 & 4,41 & 0,896 \\
\hline 23 & $\begin{array}{l}\text { A Apple me trata como um } \\
\text { cliente importante. }\end{array}$ & 1 & 5 & 4 & 3 & 3,50 & 1,237 \\
\hline 24 & $\begin{array}{l}\text { Minhas experiências de } \\
\text { compra com a } \\
\text { Apple superam minhas } \\
\text { expectativas. }\end{array}$ & 1 & 5 & 4 & 5 & 3,94 & 1,103 \\
\hline 25 & Identifico-me com a Apple. & 1 & 5 & 4 & 5 & 3,94 & 1,145 \\
\hline 26 & $\begin{array}{l}\text { A Apple me trata com } \\
\text { respeito. }\end{array}$ & 1 & 5 & 4 & 3 & 3,87 & 0,966 \\
\hline 27 & $\begin{array}{l}\text { A Apple me oferece } \\
\text { atendimento personalizado. }\end{array}$ & 1 & 5 & 3 & 3 & 3,45 & 1,220 \\
\hline 28 & $\begin{array}{l}\text { Os smartphones vendidos } \\
\text { pela Apple têm bom valor } \\
\text { (os benefícios excedem os } \\
\text { custos). }\end{array}$ & 1 & 5 & 4 & 4 & 3,55 & 1,232 \\
\hline 29 & $\begin{array}{l}\text { A Apple é eficiente na } \\
\text { solução de problemas. }\end{array}$ & 1 & 5 & 4 & 5 & 3,90 & 1,049 \\
\hline 30 & $\begin{array}{l}\text { A Apple procura conhecer } \\
\text { minhas preferências. }\end{array}$ & 1 & 5 & 4 & 4 & 3,64 & 1,069 \\
\hline 31 & $\begin{array}{l}\text { A Apple recompensa minha } \\
\text { fidelidade. }\end{array}$ & 1 & 5 & 3 & 3 & 2,89 & 1,305 \\
\hline 32 & $\begin{array}{l}\text { Estou disposto a comprar } \\
\text { outros produtos/serviços da } \\
\text { Apple. }\end{array}$ & 1 & 5 & 5 & 5 & 4,28 & 1,084 \\
\hline 33 & $\begin{array}{l}\text { A Apple possui boas } \\
\text { instalações (físicas e } \\
\text { virtuais). }\end{array}$ & 1 & 5 & 5 & 5 & 4,36 & 0,939 \\
\hline 34 & $\begin{array}{l}\text { Os smartphones vendidos } \\
\text { pela Apple são de alta } \\
\text { qualidade. }\end{array}$ & 2 & 5 & 5 & 5 & 4,67 & 0,569 \\
\hline
\end{tabular}

Fonte: dados da pesquisa

Por fim, foram analisadas as correlações entre as variáveis para verificar a possibilidade de utilização de regressão múltipla. Todas as correlações foram positivas e significativas com exceção da correlação entre percepção do relacionamento e significado simbólico. No que diz respeito à intensidade da associação, todas as correlações existentes apresentaram baixa ou moderada associação de acordo com Cohen (1992). O autor defende que valores de 0,1 a 0,29 apresentam baixa associação, valores de 0,3 a 0,49 apresentam associação moderada e acima de 0,5, forte associação. A Tabela 6 apresenta esses resultados.

REAd | Porto Alegre - Edição 80 - N 1 - janeiro/abril 2015 - p. 170-199 
Marketing de relacionamento com a Apple: o papel do julgamento e significado de produto na escolha do iPhone

Tabela 6 - Correlações entre as variáveis da pesquisa

\begin{tabular}{|c|c|c|c|c|c|}
\hline \multirow[b]{2}{*}{ Fatores } & \multicolumn{5}{|c|}{ Correlações } \\
\hline & $\begin{array}{c}\text { Julgamento } \\
\text { Passo-a- } \\
\text { Passo }\end{array}$ & $\begin{array}{c}\text { Julgamento } \\
\text { Afetivo }\end{array}$ & $\begin{array}{c}\text { Significado } \\
\text { Simbólico }\end{array}$ & $\begin{array}{c}\text { Significado } \\
\text { Utilitário }\end{array}$ & $\begin{array}{l}\text { Percepção do } \\
\text { Relacionamento }\end{array}$ \\
\hline $\begin{array}{c}\text { Julgamento } \\
\text { Passo-a-Passo }\end{array}$ & 1 & & & & \\
\hline $\begin{array}{l}\text { Julgamento } \\
\text { Afetivo }\end{array}$ & $0,163^{*}$ & 1 & & & \\
\hline $\begin{array}{l}\text { Significado } \\
\text { Simbólico }\end{array}$ & $-0,163^{*}$ & $0,489^{* *}$ & 1 & & \\
\hline $\begin{array}{c}\text { Significado } \\
\text { Utilitário }\end{array}$ & $0,199^{* *}$ & $0,340^{* *}$ & $0,241^{* *}$ & 1 & \\
\hline $\begin{array}{l}\text { Percepção do } \\
\text { Relacionamento }\end{array}$ & $0,183^{* *}$ & $0,372^{* *}$ & 0,061 & $0,279^{* *}$ & 1 \\
\hline
\end{tabular}

Nota. *. Correlação significante no nível de 0,05

**. Correlação significante no nível de 0.01

Fonte: dados da pesquisa

Por conseguinte, considerando as correlações significativas entre a maioria das variáveis $(p<0,01$ ou $p<0,05)$, recomenda-se estimar relações de predição entre as variáveis por meio de regressão múltipla linear (FIELD, 2009).

A Tabela 7 sumariza os resultados da regressão múltipla, tendo como variável independente os tipos de julgamento e significado de produto e a percepção do relacionamento como variável dependente.

Tabela 7 - Resultados da regressão múltipla linear

\begin{tabular}{|c|c|c|c|c|c|c|c|}
\hline $\begin{array}{c}\text { Variável } \\
\text { Dependente } \\
\text { (VD) }\end{array}$ & $\begin{array}{c}\text { Variável } \\
\text { Independente } \\
\text { (Vi) }\end{array}$ & $\mathbf{R}$ & $\mathbf{R}^{2}$ & Variáveis & $\boldsymbol{\beta}$ & sig & $\begin{array}{c}\text { Teste } \\
\text { Estatístico }\end{array}$ \\
\hline \multirow{2}{*}{$\begin{array}{l}\text { Percepção do } \\
\text { Relacionamento }\end{array}$} & \multirow{2}{*}{$\begin{array}{l}\text { Julgamento e } \\
\text { Significado de } \\
\text { Produto }\end{array}$} & \multirow{2}{*}{0,47} & \multirow{2}{*}{0,191} & $\begin{array}{c}\text { Julgamento } \\
\text { Passo-a-Passo } \\
\text { Julgamento } \\
\text { Afetivo }\end{array}$ & 0,379 & 0,382 & \multirow[t]{2}{*}{$\mathrm{F}=11,595$} \\
\hline & & & & $\begin{array}{c}\text { Significado } \\
\text { Simbólico } \\
\text { Significado } \\
\text { Utilitário }\end{array}$ & 0,176 & 0,013 & \\
\hline
\end{tabular}

Fonte: dados da pesquisa

A partir dos resultados engendrados, a contribuição dos fatores referentes a julgamento e significado na explicação da variável dependente foi de 19\%, que, pelo entendimento de Cohen (1992), é considerado de médio efeito. O autor afirma que a interpretação dada para a significância estatística do coeficiente de determinação de uma regressão $\left(\mathrm{R}^{2}\right)$ no âmbito das ciências comportamentais, considera-se $2 \%$ como um pequeno REAd | Porto Alegre - Edição 80 - N 1 - janeiro/abril 2015 - p. 170-199 
efeito, $13 \%$ como um médio efeito e a partir de $26 \%$ um grande efeito. Ao desmembrar os fatores da variável dependente, é possível afirmar que o julgamento passo-a-passo, o julgamento afetivo e o significado utilitário possuem uma correspondência positiva com a percepção do relacionamento, pois apresentam o valor de beta ( $\beta$ ) maior que zero. Inversamente a estes, o fator significado simbólico apresentou uma relação negativa com a variável dependente, o que mostra uma relação inversa entre as variáveis, ou seja, o crescimento de uma acarreta o decréscimo da outra.

Dentre os fatores, o julgamento afetivo foi o melhor preditor de percepção do relacionamento $(\beta=0,379)$, seguido do significado utilitário $(\beta=0,176)$. O julgamento passo-apasso contribuiu de maneira tímida para a explicação da percepção de relacionamento $(\beta=0,061)$. Em outras palavras, o julgamento baseado em emoções explica cerca de $38 \%$ do relacionamento com uma marca, no caso a Apple. Isso demonstra que mesmo que os usuários pesquisados julguem predominantemente de maneira racional o iPhone quando da sua aquisição, o que efetivamente influencia e é preponderante para uma melhor percepção do relacionamento com a marca é o julgamento afetivo, baseado mais em emoções que em informações, priorizando o intangível, o afeto e a identificação com a marca (ALLEN, 2001).

Contudo, houve um resultado inesperado. Baseando-se na teoria, contava-se que a atribuição de significado simbólico apresentasse um valor de beta alto e positivo, pois, de acordo com Alfinito et al (2012), há relação positiva entre julgamento afetivo e significado simbólico. $O$ valor negativo de beta encontrado $(\beta=-0,156)$ não correspondeu às expectativas, mostrando uma relação oposta entre a percepção do relacionamento e o significado simbólico. Pode-se aventar que mesmo os consumidores baseando-se mormente em aspectos utilitários e funcionais na compra do iPhone (ex: maior quantidade de aplicativos, portabilidade, etc), as experiências e símbolos (ex: status, força da marca) associados ao smartphone também acabam influenciando a intenção d erecompra, o que se traduz em um relacionamento de longo prazo.

Como à luz da teoria visitada, não há explicações para este resultado e ainda considerando que este estudo é pioneiro em estudar as relações entre as variáveis propostas, mais pesquisas fazem-se necessárias para refutar ou corroborar o que foi por ora encontrado e melhor entender este resultado específico. Se tal resultado for confirmado em pesquisas subsequentes, um novo arcabouço teórico pode ser construído e novas teorias induzidas.

O objetivo principal deste estudo foi verificar se o julgamento e significado atribuído ao iPhone são preditores da percepção do relacionamento com a Apple. Tal objetivo foi 
Marketing de relacionamento com a Apple: o papel do julgamento e significado de produto na escolha do iPhone

atingido por meio de uma análise de regressão múltipla linear, observando-se no estudo que as variáveis independentes apresentaram efeito médio sobre a variável dependente.

Dentre as variáveis independentes, o julgamento afetivo foi o melhor preditor da percepção do relacionamento com a marca. Isso evidenciou que os usuários pesquisados percebem um melhor relacionamento com a Apple na medida em que escolhem o produto iPhone predominantemente a partir de critérios afetivos e atributos intangíveis (ex: o produto deixa o usuário de bom humor ao usá-lo, o produto reflete o jeito de ser do usuário, o sentimento em relação ao produto, etc).

No que diz respeito aos demais objetivos, foi possível concluir que os usuários predominantemente são influenciados pelo julgamento passo-a-passo e dão mais importância ao significado utilitário no processo de escolha e compra do iPhone. Esse resultado comprovou a teoria que relaciona positivamente o julgamento passo-a-passo com o significado utilitário. Quanto à percepção do relacionamento com a Apple, os respondentes mostraram que a alta qualidade dos smartphones vendidos pela marca e a confiança pela mesma são os fatores mais preponderantes na sua escolha.

\section{CONSIDERAÇÕES FINAIS}

Uma pesquisa científica precisa fazer contribuições acadêmicas e práticas, haja vista que a administração é uma ciência essencialmente aplicada. Este trabalho contribuiu para o avanço nos estudos tanto da área de marketing como também de comportamento do consumidor, ao evidenciar a relação entre as variáveis de marketing de relacionamento e julgamento e significado de produto, interatividade esta que ainda não havia sido explorada em outros estudos. Ademais, sob uma perspectiva prática e gerencial para a Apple ou outras fabricantes de smartphones, os resultados podem ser utilizados como diagnóstico que subsidiem as tomadas de decisões dos gestores quanto às suas estratégias de promoção de produtos e fidelização de clientes.

No tocante às limitações e subsequentes recomendações para estudos futuros, a natureza transversal do estudo não permite nenhuma inferência quanto à causalidade das relações estudadas, indicando apenas sua direção e magnitude. Pesquisas transversais também comprometem a generalização dos resultados. Assim, recomenda-se fortemente o desenvolvimento de uma base de dados de séries temporais permitirá o teste das relações por ora obtidas em uma perspectiva longitudinal. Interessante também seria testar o modelo de variáveis independentes e dependente desta pesquisa a partir de técnicas confirmatórias como 
a modelagem por equações estruturais.

Outra limitação acerca da amostra pode ser identificada pela limitação do alcance de distribuição do endereço eletrônico do questionário, ou seja, pelo fato da divulgação ter sido basicamente realizado pelas redes sociais, a amostra atingida ficou mais restrita aos ciclos de contatos mais próximos dos pesquisadores. Nesse sentido, validações com diferentes amostras e com características sociodemográficas diversas são importantes. Ainda, com o intuito de verificar possíveis problemas com a amostra que possuía respondentes residentes em outros países, devido às diferenças culturais, foi realizada a mesma análise, suprimindo-se esses sujeitos (13 respondentes). Os coeficientes de regressão $\left(\mathrm{R}^{2}\right)$ apresentaram uma diferença de menos de $10 \%$, sem chance de mudança de efeito das variáveis independentes sobre a variável dependente, o que evidenciou a possibilidade de continuar com a amostra inicial de 201 sujeitos sem vieses na interpretação dos resultados. Ainda, vale ressaltar que a maioria desses sujeitos tratava-se de brasileiros residentes em outros países.

Além disso, como não houve qualquer estudo comparativo com outros smartphones de outras marcas, não se pode concluir que os resultados obtidos também não possam ocorrer em relação a aparelhos das mais diversas marcas. Ou seja, o comportamento identificado nos usuários pesquisados pode não ser exclusivo para o iPhone de sorte que se recomenda a realização de estudos com outras marcas de smartphones para viabilizar comparações e obter resultados mais conclusivos acerca dos achados relativos ao iPhone.

A observação de um resultado não esperado na análise de regressão realizada, no que se refere ao significado simbólico em relação à percepção do relacionamento com a marca de acordo com a teoria visitada é outra limitação do estudo, exigindo mais esforços voltados para a sua compreensão. Ou seja, a realização de estudos mais aprofundados e específicos sobre a predição do julgamento e significado de produto, no que diz respeito à percepção do relacionamento, de forma a possibilitar um melhor entendimento da relação entre as variáveis. Nesse sentido, trabalhos de natureza multimétodo possibilitariam um maior aprofundamento de resultados, pois iriam além das medições das variáveis para a compreensão do porquê das relações encontradas.

Adicionalmente, as revisões da produção nacional realizadas para as duas variáveis da pesquisa mostraram que ainda há espaço para pesquisas sobre CRM, especialmente de natureza multimétodo, voltadas para o setor público e/ou terceiro setor e também de ensaios teóricos que explorem as dimensões, os pressupostos, os conceitos e as tendências do CRM. No que diz respeito ao Julgamento e Significado de Produto, a produção em periódicos é 
Marketing de relacionamento com a Apple: o papel do julgamento e significado de produto na escolha do iPhone

bastante incipiente e concentrada em poucos grupos de pesquisa, o que significa um pujante horizonte de possibilidades de investigações científicas.

Por fim, não obstante as limitações por ora apresentadas, esse estudo alcançou seu objetivo ao ser pioneiro em apresentar as relações entre importantes variáveis das áreas de marketing e comportamento do consumidor, o que constituía uma lacuna na literatura. Os resultados produzidos e apresentados não têm a pretensão de serem conclusivos ou limitantes de modo que novos estudos precisam ser realizados sob diferentes perspectivas metodológicas. Assim, será possível contribuir para o avanço progressivo do conhecimento teórico-empírico a respeito de como os consumidores escolhem produtos e como esse processo de decisão de compra influencia o estabelecimento de relacionamentos de longo prazo com empresas e marcas em um panorama de intensa competitividade.

\section{REFERÊNCIAS}

AGARIYA, A. K.; SINGH, D. CRM Index development and validation in Indian banking sector. International Journal of Customer Relationship Marketing and Management, $3(2), 10-32,2012 b$.

AGARIYA, A. K.; SINGH, D. CRM Scale development \& validation in Indian insurance sector. Journal of Internet Banking and Commerce, 17(2), 1-21, 2012a.

AGARIYA, A. K.; SINGH, D. CRM scale development and validation scale in Indian public hospitals. Journal of Health Management, 15(2), 275-291, 2013.

ALFINITO, S.; NEPOMUCENO, M. V.; TORRES, C. V. Avanços no desenvolvimento da escala de julgamento e significado do produto para o Brasil. Revista Brasileira de Marketing, v. 11, n. 2, p. 152-177, 2012.

ALFINITO, S.; TORRES, C. V.. Modelo de influência cultural no consumo: Uma proposta baseada em axiomas sociais. Revista de Administração Mackenzie, v. 13, n. 15, p. 15-38, 2012.

ALLEN, M. W. A practical method for uncovering the direct and indirect relationships between human values and consumer purchases. Journal of Consumer Marketing, v. 18, n. 2, p. 102-120, 2001.

ALLEN, M. W. The attribute-mediation and product meaning approaches to theinfluences of human values on consumer choices. In F. Columbus (Ed), Advances in Psychology

Research, vol. 1, 31-76. Huntington, NY: Nova Science Publishers, 2000.

ALLEN, M. W. The direct and indirect influences of human values on consumer choices. Unpublished Ph.D. Thesis, University of Wellington, New Zealand, 1997.

REAd | Porto Alegre - Edição 80 - N 1 - janeiro/abril 2015 - p. 170-199 
ALLEN, M. W.; NG, S. H. The direct and indirect influence of human values on product ownership. Journal of Economic Psychology, v. 20, n. 1, p. 5-39, 1999.

BENOUAKRIM, H.; EL KANDOUSSI, F. Relationship marketing: literature review. International Journal of Science and Research, v. 2, n. 10, p. 148-152, 2013.

BRAND KEYS. 2014 Customer Loyalty Engagement Winners. Disponível em <http://www.brandkeys.com>. Acesso em 10 fev. 2014.

BREI, V. A.; ROSSI, C. A.. Confiança, valor percebido e lealdade em trocas relacionais de serviço: um estudo com usuários de internet banking no Brasil. Revista de Administração Contemporânea, 9(2), 152-163. 2005.

BYGSTAD, B. The implementation puzzle of CRM systems in knowledge-based organizations. Information Resources Management Journal, 16(4), 33-45, 2003.

CAMPBELL, A. J. Creating customer knowledgement competence: managing customer relationship management programs strategically. Industrial Marketing Management, 32, 375-383, 2003.

CARTA CAPITAL. Mais Admiradas 2013. Disponível em <http://www.cartacapital.com.br>. Acesso em 05 nov. 2013.

COCHRAN, W. G. Sampling techniques. 3. ed. New York: John Wiley \& Sons, 2007.

COHEN, J. A power primer. Psychological Bulletin, v. 112 n. 1, 133-159, 1992.

DEMO, G. B2C Market: Development of a CRM Scale. In: Ali Ghorbani. (Ed.). Marketing in the Cyber Era. Hershey, PA: IGI Global, p. 85-95, 2014.

DEMO, G.; ROZZETT, K. Customer Relationship Management Scale for the Business-toConsumer Market: Exploratory and Confirmatory Validation and Models Comparison. International Business Research. Canadá, p. 29-42. set. 2013.

DEMO, G.; ROZZETT, K. O.; PONTE, J. V. A.; FERREIRA, L. A.; MENDES, N.M.D. Marketing de Relacionamento (CRM): Estado da arte, produção nacional na primeira década do milênio e agenda de pesquisa. In: Encontro da Associação Nacional de Pós-Graduação e Pesquisa em Administração, 35. Rio de Janeiro. Anais... Rio de Janeiro: ANPAD, 2011.

EPSTEIN, S. Integration of the cognitive and the psychodynamic unconscious. American Psychologist, 49(8), 709-724, 1994.

ERNST, H.; HOYER, W.; KRAFFT, M.; KRIEGER, K. Customer relationship management and company performance: the mediating role of new product performance. Journal of the Academy of Marketing Science, 39(2), 290-306, 2011. 
Marketing de relacionamento com a Apple: o papel do julgamento e significado de produto na escolha do iPhone

FARIA, L. H. L.; GIULIANI, A. C.; PIZZINATO, N. K.; SPERS, V. R. E. 20 anos de publicações sobre marketing de relacionamento no Brasil: uma análise da produção acadêmica de 1992 a 2012. Revista Brasileira de Marketing, v. 13, n. 1, p. 106-118, 2014.

FIELD, A. Descobrindo a estatística usando o SPSS. Porto Alegre: Artmed, 2009.

FORTUNE MAGAZINE. Most Admired Companies. Disponível em <http://www.money.cnn.com/magazines/fortune>. Acesso em 13 jun. 2013

FOURNIER, S. Measuring-based framework for the study of consumer-object relations. Advances in Consumer Research, 18, 736-742, 1991.

GRÖNROOS, C. From marketing mix to relationship marketing. Management Decision, 32(2), 4-20, 1994.

GUPTA, A.; SAHU, G. P. A literature review and classification of relationship marketing research. International Journal of Customer Relationship Marketing and Management, v. 3, n. 1, p. 56-81, 2012.

HAIR JR., J.F.; BABIN, B.; MONEY, A.H.; SAMOUEL, P. Fundamentos de métodos de pesquisa em administração. Tradução Lene Belon Ribeiro. Porto Alegre: Bookman, 2005. 471p.

HAIR, J. F.; BLACK, W. C.; BABI, B. J.; ANDERSON, R. E.; TATHAM, R. L. Análise multivariada de dados. 6. ed. Porto Alegre: Bookman, 2009.

HUANG, J.; XIONG, W. The effect of win-back investment on lost consumers' intention of reinitiating relationship. Frontiers of Business Research in China, v.4, n.3, p. 485-497, 2010.

IGLESIAS, O.; SAUQUET, A.; MONTAÑA, J. The role of corporate culture in relationship marketing, European Journal of Marketing, v. 45, n. 4, p. 631-650, 2011.

INTERBRAND. Best Global Brands. Disponível em <http://www.interbrand.com>. Acesso em 02 jun. 2013.

KUMAR. V.; JONES, E.; VENKATESAN, R.; LEONE, R. P. Is market orientation a source of sustainable competitive advantage or simply the cost of competing? Journal of Marketing, 75(1), 16-30,2011.

LEVY, S. Post-encephalitic behavior disorder: a forgotten entity: a report of 100 cases. The American Journal of Psychiatry, v.115, n. 2, p.1062-7. 1959. 
MENDES, L. A. C.; NASCIMENTO, D. A. M.; COUTINHO, M. L.; SOUZA FILHO, J. F.; FREIRES, L. A.. Avaliações postais: Uma explicação no julgamento e significado dos serviços. In Universidade Mackenzie (Org.), Brasil, 2011.

MISHRA, A.; MISHRA, D. Customer Relationship Management: implementation process perspective. Acta Polytechnica Hungarica, 6(4), 83-99, 2009.

MITTAL, B. The role of affective choice mode in the consumer purchase of expressive products.Journal of Economic Psychology, 9, 499-524, 1988.

NEPOMUCENO, M. V.; PORTO, R. B.; RODRIGUES, H.. Avanços teóricos e metodológicos das pesquisas sobre julgamento e significado do produto no Brasil. Revista Psicologia Organizações e Trabalho, 6(1), 106-137, 2006.

NEPOMUCENO, M. V.; TORRES, C. V. Validação da escala de julgamento e significado do produto. Estudos de Psicologia (Natal), 10(3), 421-430, 2005.

NGAI, E. W. T. Customer relationship management research (1992-2002): an academic literature review and classification. Marketing intelligence \& planning: v. 23, n. 6/7, p. 582$605,2005$.

NGAI, E. W. T.; XIU, L.; CHAYU, D. C. K. Application of data mining techniques in customer relationship management: a literature review and classification. Expert systems with applications: v. 36, p. 2592-2602, 2009.

ÖZTAYSI, B.; SEZGIN, S.; ÖZOK, A. F. A measurement tool for customer relationship management processes. Industrial Management \& Data Systems, 111(6), 943-960, 2011.

PAYNE, A. Handbook of CRM: achieving excellence in customer relationship management. Oxford: Elsevier, 2006.

PORTER, M. E. Towards a dynamic theory of strategy. Strategic Management Journal, v.12, p. 95-117, 1991.

REICHHELD, F. F. Learning from customer defections. Harvard Business School Press, 74, 56-69, 1996.

REICHHELD, F. F.; SASSER Jr, W. E. (1990). Zero clientes perdidos: a qualidade chega aos serviços. In: SHAPIRO, B. P.; SVIOKLA, J. J. Mantendo clientes. São Paulo: Makron Books, 1995.

RICHINS, M. L. Valuing things: the public and private meanings of possessions. Journal of Consumer Research, 21, 504-521, 1994.

ROZZETT, K.; DEMO, G. Desenvolvimento e validação da Escala de Relacionamento com Clientes (ERC). Encontro Nacional de Engenharia de Produção, São Carlos, SP, Brazil,

REAd | Porto Alegre - Edição 80 - N 1 - janeiro/abril 2015 - p. 170-199 
Marketing de relacionamento com a Apple: o papel do julgamento e significado de produto na escolha do iPhone

Outubro, 2010a.

ROZZETT, K.; DEMO, G.. Desenvolvimento e validação da Escala de Relacionamento com Clientes (ERC). Revista Administração de Empresas, 50(4), 383-395, 2010b.

ROZZETT, K.; DEMO, G. Escala de Relacionamento com Clientes (ERC): validação fatorial confirmatória por meio da modelagem por equações estruturais. In Congresso

Iberoamericano de Psicologia das Organizações e do Trabalho, 2. Florianópolis: SBPOT, 2011.

SALGANIK, M. J.; HECKATHORN, D.D. Sampling and estimation in hidden populations using respondent-driven sampling. Sociological Methodology, v. 34, p. 193-240, 2004.

SHETH, J. N.; PARVATIYAR, A. Evolving relationship marketing into a discipline. Journal of Relationship Marketing, v. 1, n. 1, p. 3-16, 2002.

SIN, L. Y. M; TSE, A. C. B; YIM, F. H. K. CRM: conceptualization and scale development. European Journal of Marketing, v. 39, n. 11/12, p. 1264-1290, 2005.

SOCH, H.; SANDHU, H. S. Does Customer Relationship Management affect firm performance? Global Business Review, v. 9, n. 2, p. 189-206, 2008.

SOJAN, S.; RAPHY, S. K.; THOMAS, P. Techniques used in decision support system for $\mathrm{CRM}$ - a review. Interational Journal of Information Technology Infrastructure, v. 3, n. 1, p. 9-12, 2014.

TABACHNICK, B. G.; FIDELL, L. S. Using multivariate statistics. 5. ed. Boston: Pearson Allyn And Bacon, 2007.

VIANA, D. A.; CUNHA JR, M. V. M.; SLONGO, L. A.. Medindo o conceito de marketing de relacionamento no contextobrasileiro: a validação de umaescala no setor industrial. Anais do Encontro da ANPAD, Brasília, DF, Brazil, 29, 2005.

WAHLBERG, O; STRANDBERG, C; SUNDBERG, H; SANDBERG, K. W. Trends, topics and under-researched areas in CRM research: a literature review. International Journal of Public Information Systems, Sundsvall, v. 3, p. 191-208, 2009.

WANG, Y.; FENG, H. CRM capability in service industries: conceptualization and scale development. Proceedings of 2008 IEEE International Conference on Service Operations and Logistics, and Informatics, Beijing, China, 2008.

WILSON, E. J.; VLOSKY, R. P. Partnering relationship activities: building theory from case study research. Journal of Business Research, v.39, n. 1, p. 59-70, 1997.

ZABLAH, A. R.; BELLENGER, D. N.; JOHNSTON, W. J. An evaluation of divergent REAd | Porto Alegre - Edição 80 - Nº 1 - janeiro/abril 2015 - p. 170-199 
Gisela Demo \& Morgana Guanabara

perspectives on customer relationship management: towards a common understanding of an emerging phenomenon. Industrial Marketing Management, v.33, p. 475-489, 2004.

ZULKIFLI, Z.; TAHIR, I. M. Developing and validating Customer Relationship Management (CRM) practices construct. International Journal of Business and Behavioral Sciences, v.2, n.1, p. 35-48, 2012. 